\title{
The importance of fantasy as a resource in the period of adolescence - innovative techniques for a clinical mediator's use - time tunnel game
}

\section{The process of creating the time tunnel kit}

"Teenagers have a certain limitation concerning their verbal expression, revealing difficulties to differentiate and denominate concepts, affections, feelings, thoughts and emotions. It seems to lack significant vocabulary to represent what they are living, feeling or thinking".

The Time tunnel kit is an instrument developed due to an increasing demand in my clinical practice concerning adolescents and pre- adolescents for the past 20 years.

I began to gradually elaborate and apply the kit throughout the medical assistance given to patients that would enter the room resistant to the use of a ludic child material and in some cases even averse to drawing as a resource, claiming that such psychotherapeutic techniques were "childish things". However, those adolescents would still express immaturity when facing conventional verbalization of feelings as the ones exercised with adults.

Therefore, it is appropriate to question ourselves if it is possible to proceed with the insertion of infant techniques and/or adult patients for the clinical care of adolescents. Expressions through drawing are great channels for younger adolescents, although in clinical contexts it is common to listen from 16 years- older ones: "Don't even bring me those drawings!"-a reinforcing statement to report technical inadequacy.

Usually, the adolescent and pre-adolescent do not seek psychotherapeutic treatment spontaneously. It generally happens with an intervention of the parents, a psychopedagogue, teachers and/ or a family physician, therefore showing little or no motivation for treatment and quite often displaying an obvious suffering. While psychotherapists we are aware of the difference between the adolescent that arrives in the office brought by someone and the one that recognizes that "is not feeling so well" and then ask his or her caretaker to pursue assistance from a professional in the psychology area.

When facing such clinical cases the professional is aware that the exclusive use of verbal communication is, at its most, impracticable and there is a need for creating a mediator or mediators that facilitate to adolescents and pre-adolescents the expression and symbolization of their own feelings. Besides the expression of affections, it is the responsibility of the psychologist to comprehend the dynamics of the family in which the patient is included, as well as the place that this teenager holds in this group. Nonetheless, exploring and awaiting for the verbalization of these information can be stressful and present poor results in several clinical cases. Freitas, ${ }^{1}$ presents us a reflection over the fundamental responsibility of the psychotherapist in the clinical assistance of adolescents:

The work developed with the adolescent, whichever theoretical framework it may follow, cannot come before an examination of
Volume 2 Issue 5 - 2018

Maria Salete Arenales Loli
Universidade Estadual Paulista, Brazil

Correspondence: Maria Salete Arenales Loli, Universidade Estadual Paulista, Brazil, Email msarenalasloli@gmail.com

Received: March 24, 2018 | Published: November 22, 2018

the family and their social conditions, given the fact that the critical situations they go through are intimately related to difficulties in the family group.

I personally feel uncomfortable when using classical ludic games, as quite often they usually disperse the focus of our assistance: the facts, feelings and agonies. It is certain that such latent matters will present themselves throughout these games. However, it is more similar to the work of a prospector in the middle of a great mud flood, where you eventually find a few lost gold nuggets. Despite the clinical material that such games might provide to the psychotherapeutic process, its routine application might favor the emergency of other substances in service of resistance, as well pointed by Garcia. ${ }^{2}$ Thus, my choices for facilitators of contact were clay, play dough, cutouts of magazines for expressing specific feelings. Although a more direct and incisive approach was still lacking in this dialogue with the adolescent and pre-adolescent.

From my clinical experience, I observed that adolescents are frequently anxious and anguished before long silences in sessions. The experiences reported by a number of patients in their adolescence during the process of psychotherapy were helpful and nowadays, in the position of adults, they "complain" of the difficulty in describing their feelings at that time and the anxiety mobilized in long silences from their psychotherapists, emphasizing that this was a decisive factor for abandoning their treatment at that time. It is worth wondering why should we incur in the same mistake when those adults of today are freely giving us these precious information about technical details concerning this specific population.

Propelled by the yearning of putting myself in a more directive and active role while psychotherapist for adolescents and initially inspired by the results and willingness of these adolescents in filling the incomplete sentences of Rodolfo Bohoslavsky, ${ }^{3}$ in "Orientacion Vocacional" (Vocational Orientation), I have created and developed the game "Time tunnel"- based on the peculiar needs of this age group focusing on the clinical context. In the beginning, the game started with only incomplete sentences and I gradually noticed the need to include the ludic in these sentences, coming to conclude that the changes were considerably productive as further discussed in the summary of this piece.

Garcia ${ }^{2}$ observes that "in general outlines, adolescents tend to be more superficial when accessing their feelings" and highlights 
something fundamental: that he does not see this characteristic as constantly related to a pathology but as a way of common organization in this moment of their development.

Thus, the assistance of adolescents and pre-adolescents would demand major technical modifications from the psychotherapist in the psychotherapeutic process, which does not match with the child ludic approach or to the verbal report of the adult and given the determination of this need, the Time tunnel kit was gradually created.

The Kit approaches three basic themes: past, present and future. The questions concerning the past help the adolescent with recapitulations and expressions of content that under psychotherapeutic treatment might enable the teenager to reconstruct significant facts with psychological relevance.

The Present theme provides a reflection over the self in its present condition as a self- observation and amplification of self- awareness in their reality. It is frequently observed in clinical assistances that adolescents and pre-adolescents find themselves with difficulty in expressing their daily routine to the psychotherapist: who are their friends, their school routine, how their school breaks work, how friendship, home and other types of resistances are handled. This way, sentences of the present allow the teenager to establish a greater contact with him/herself, the self- consciousness over the possibilities and limitations they have and the expansion of a great set of information to the psychotherapist that would not be able to be transmitted in any other way.

The Future revives the vision of temporality, of looking forward and ahead, which is usually an inaptitude for the youngster. This theme allows the discovery of abilities yet to be developed, something fundamental to be stimulated by the professional that is accompanying and individual of this age group.

Another time theme denominated "Cases and Chances" holds the primary objective of instigating the imagination of the adolescent and harnesses its content for the psychotherapeutic process.

One example of these incomplete sentences is: "The Genie in the Bottle showed himself for you and asked you to make three wishes... Which would that be?" It was frequently observed that the wish for psychotherapy arises in that moment, expanding the possibility of comprehending the psychotherapeutic process by the adolescent, consequently strengthening the bond with the psychotherapist.

When the game requests something, if the teenager is playing or fantasizing, that content can be expressed by him through drawing or fantasy in a smoother way once the thematic is distant from reality itself.

Thus, it is essential that the professional is involved with the questions asked in the game and incentives the adolescent to fantasize through it, especially when dealing with cards that suggest this type of approach, meaning magical powers amongst other fantasies and/ or imaginations.

Corso and $\mathrm{Corso}^{4}$ wrote when referring to the adolescence portrayed in Harry Potter:

[...] Playing, for the child and fantasizing for the teenager are resources of elaboration, where the subject gets in touch with his ideals and conflicts in a light and uncommitted way. There is no need to deal with the consequences lived in these scenes, since playing or daydreaming imply that the subject is out of reality.

Corso and $\mathrm{Corso}^{4}$ emphasize that marvelous tales are never gentle and might handle subjects with a lot of rawness "thanks to the distancing allowed by the fantasy". These authors understand that perhaps this distance is there due to this exact fact.

Sensitive topics will eventually be covered inside the psychotherapeutic process and the expression through distant depiction of the question itself might help dealing with the issue and diminish the agony.

Whenever children wish to handle certain subjects, they would naturally use the resource of distancing themselves from the facts. They report events as if they were not related to them and attribute their serious aspects to a friend, a sibling or a pet. Although we are aware that the child is the real protagonist, he must not be exposed. This is a classic example of supporting a communication that, in its objective form would be struggling and embarrassing.

In a description of a clinical case, Blos ${ }^{5}$ mentions Judy, a 16 year-old adolescent who did not hesitate to share with her therapist that she had been fantasizing about a boy and reported a fad amongst the girls at school that favored their need to daydream. The fad consisted in imagining stories of a "paper boyfriend"- which means an inexistent boyfriend, however created by the girl to talk about him with other people.

That would allow a girl to talk of a boyfriend without having one and at the same time without lying, as the others were aware that it was "play pretended". At times, reality and fiction would mix- as for example the time when all the girls in the group including Judy were extremely involved with the engagement of one of them, until she realized that it was all but a "paper engagement".

In clinical assistances for children, ludic resources must be available in order to reach a universe that lies beyond words. The same is worth for adolescents, as there is the need for resources to extract a universe that is closer to words when compared to the one of a child but in most cases still requires the use of mediators. Instigating and exploring the imagination becomes an important channel for the clinical work with adolescents.

In his thesis, Tardivo ${ }^{6}$ determines the importance of fantasizing to teenagers and stresses the suffering of those who do not take advantage of this resource, stating, "How difficult life is when the teenager stops dreaming (...). How can one defend himself then?"

On the other hand, the adolescent that is not chronically ill still has a lot of imagination and fantasy present in his life and these resources become channels of great importance to both psychodiagnostic and psychotherapeutic processes when explored by the professional Arenales-Loli?

The adolescent is the one that seeks a new place in the world and some of them feel extremely lost during this quest. Adolescence is the period where the human being reorganizes himself for structuring as a person. It is a time when they are preparing for the future, to constitute a new family, decisions of professional choice and formation, among other changes and settings. Psychotherapy offers to the teenager an opportunity to reflect, to consider consequences, facts and attitudes in a moment where acting overcomes thinking. 
Lastly, they are packing their bags for the journey of their own lives, they will soon take off and great part of the directions taken will depend on the decisions made in this period of great immaturity. To speak and depict oneself as desirable and fearful at the same time; and then to the psychotherapist that is committed to assist them in "packing the bags for this great trip in search of the future" remains an agonizing territory between the pursuit of questioning without invading, silencing without unnerving and communicating yourself clearly in order to provide the identification and comprehension of feelings Levisky. ${ }^{8}$

\section{Acknowledgements}

None

\section{Conflict of interest}

The author declares there is no conflict of interest.

\section{References}

1. Freitas LAP. Adolescence, Family And Drugs: The Parental Function And The Question Of Limits. Rio de Janeiro: Mauad; 2002.
2. Garcia JC. Pre-Adolescent Analytical Experience: Dynamic Interactive Method. In: Challenges for the Psychoanalytic Technique. São Paulo: Psychologist's House; 2007.103-109.

3. Bohoslavsky R. Vocational Guidance: The Clinical Strategy. 7th Ed. São Paulo: Martins Fontes; 1987.

4. Corso DL, Corso M. Fairies On The Club: Psychoanalysis In Children's Stories. São Paulo: Artemed; 2006.

5. Blos P. On Adolescence: A Psychoanalytic Interpretation. New York: The Free Press Of Glencoe; 1962.

6. Late LS, From LPC. The Adolescent And Emotional Suffering In Today's Days: Psychological Reflections - Encounters And Travels; 2004. Thesis (Free Teaching In Psychopathology) - Institute Of Psychology; University of Sao Paulo; Sao Paulo; 2004.

7. Arenales-Loli MS. Psychotherapeutic Care With Teens: Technical Innovations With The Use Of Clinical Mediator - Time Tunnel Game. 2014. 178 F. Thesis (Doctorate in Psychology) - Faculty of Sciences and Letters; Paulista State University; Assis; 2014.

8. Levisky DL. Adolescence: Psychoanalytic Reflections. 3rd. Ed. São Paulo: Casa do Psicólogo; 2009. 